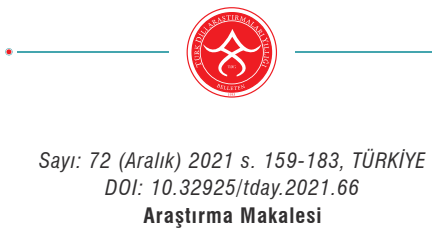

\title{
RELATIONSHIP BETWEEN DIALECT FEATURES AND LOCAL SUB GROUPS
}

\author{
Semra GÜNAY AKTAŞ *-Erdoğan BOZ **- \\ Yeliz MERT KANTAR ${ }^{* * *}$-Ayşe OKUYUCU***
}

\begin{abstract}
The main purpose in this study is to determine the spatial pattern of some characteristic vocal tones that are used in rural areas, which are not used in today's common spoken language and written language, and also to establish whether local sub-groups by using these vocal tones. Data were collected from villages in Eskişehir locality in JuneSeptember 2013 by face-to-face interview method, after which the interview data were transcribed. In these texts, palate $\mathrm{n}(/ \mathrm{y} /)$, wheezing ha $(/ \mathrm{x} /)$ and open e (/ä/) in vocal tones were detected. According to the results; $/ \mathrm{y} /$ vocal tone and $/ \mathrm{x} /$ vocal tone show global positive spatial correlation, /ä/ vocal tone is distributed randomly over the whole region. $/ \mathrm{y} /$ vocal tone is spoken by Manavs, Yoruks and Turkmens which has also been proven by statistical methods. The spoken of $/ \mathrm{x} /$ vocal tone is significant for Yoruks and Turkmens. Turkmens use the $/ \mathrm{x} /$ vocal tone more than Yoruks. /ä/ vocal tone is more spoken by Balkan immigrants. This study is one of the first studies quantitative research method was used to understand the relationship with characteristic vocal tones and local constituents. This study provides a new quantitative research methods perspective to researchers studying on the issue of dialect features, dialectology and geolinguistics
\end{abstract}

\footnotetext{
* Prof. Dr., Anadolu University, sgunay26@gmail.com, 0000-0001-6663-6827.

** Prof. Dr., Eskisehir Osmangazi University, dr.erdoganboz@gmail.com, 0000-0002-2883-4221.

*** Prof. Dr., Eskisehir Technical University, yelizmert@gmail.com, 0000-0002-4415-6520.

**** Doç. Dr., Bilecik Seyh Edebali University, ayse.okuyucu07@gmail.com, 0000-0001-7101-8943.
} 
Keywords: Geolinguistic, dialectology, spatial autocorrelation, spatial regression, Eskişehir, Turkey.

\section{AĞIZ ÖZELLIKLERİ İLE YEREL ALT GRUPLAR ARASINDAKİ İLIŞKİ}

\section{Özet}

$\mathrm{Bu}$ çalışmada temel amaç, yerel ağızlarda kullanılan, günümüz ortak konuşma dili ve yazı dilinde kullanılmayan bazı karakteristik seslerin mekânsal örüntüsünün ve ayrıca bu sesleri kullanan yerel alt grupların belirlenmesidir. Veriler 2013 yılı Haziran ayında Eskişehir ilinin köylerinde yüz yüze görüşme yöntemi ile toplanmış, ardından görüşme verileri yazıya aktarılmıştır. Metinlerde karakteristik olarak damak n'si (/y/), hırıltılı ha (/x/) ve açık e (/ä/) seslerinin geçtiği tespit edilmiştir. Araştırmanın sonuçlarına göre; /y/ ve /x/ sesleri küresel pozitif mekânsal korelasyon göstermektedir, /ä/ sesi tüm bölgede rastgele dağılmaktadır. /y/ sesinin Manav, Yörük ve Türkmenler tarafından kullanıldığ 1 istatistiksel yöntemlerle de kanıtlanmıştır. /x/ sesi Yörükler ve Türkmenler için önemli bulunmuştur. /x/ sesini Türkmenler, Yörüklerden daha fazla kullanmaktadır. /ä/ sesi Balkan göçmenleri tarafından daha fazla kullanılmaktadır. Bu araştırma, karakteristik sesleri ve bunların yerel bileşenlerle olan ilişkisini anlamak için yapılmış ilk nicel araştırmadır. Bu çalışma geolinguistik ve ağız araştırmaları konusunda çalışan araştırmacılara yeni bir nicel araştırma yöntemi ve perspektifi sunmaktadır.

Anahtar Kelimeler: Geolinguistik, diyalektoloji, mekânsal otokorelasyon, mekansal regresyon, Eskişehir, Türkiye.

\section{Introduction}

Language constitutes the core of culture in many aspects. Indeed, language is the most common variable with which different cultural groups defend their distinctive identities. It is a tool for symbolic communication and also the most important tool for ensuring the knowledge, beliefs, values, and skills that pass down (Domosh et al., 2009, p. 106). There are 6,000 languages and many dialects recognised throughout the world (UNESCO, 2018). Some languages have disappeared, and unfortunately 300 more are expected to die out by 2100. All languages are historical and cultural heritage of humanity; hence, UNESCO defines language as "a manifestation of cultural diversity." Each language, with its own value system, philosophy, and cultural characteristics, reflects a unique point of view, and languages are as rich as one another (UNESCO, 2018). 
Naturally, each language has its own diversity and richness. Most cultural groups have their own manner of speaking, which is called "dialect". People who speak the same language are likely to not fully understand another person's dialect. For this reason, people's dialects inform us about their roots (Bent et al., 2016, p. 104). Dialects are significant clues that help us understand if a speaker is local or if they come from another place. Dialects can also represent certain beliefs, such as religious ones. Dialects tend to be grouped together in a particular place; however, their locations can change or they can disappear over time due to various factors (Teerarojanarat \& Tingsabadh, 2011, p. 363). The spatial distribution of languages and dialects is the most apparent form of the complicated human mosaic (Domosh et al., 2009, p. 109). This is of vital importance as local variations in grammar and pronunciation gradually decrease over time, leading to irreplaceable cultural, historical, scientific, and ecological losses of knowledge (UNESCO, 2018). Thus, studies on dialect variations constitute a significant part of the studies concerning not only linguistics but also the preservation of humanity's cultural heritage and ethnicities (Teerarojanarat \& Tingsabadh, 2011, p. 363).

In a political context, languages and dialects show who is heard and who is silenced. They can also give political power; for example, minorities receive education, publish books, broadcast TV and radio, maintain official correspondences, or use place names in their languages (Domosh et al., 2009, p. 109). Although place names are within the study field of linguistics due to their structural properties, they also generally relate to the spatial geography, dialect, and ethnicity of a language. It has to be underlined that the extinction of a language actually results in the loss of the ethnical and cultural identity of the respective community (Tunçel, 2000, p. 24).

Language and ethnicity can also be a factor in regional disparities. Investments are likely to be lower in areas where minority languages are spoken, and those areas are home to ethnic minorities. Dai et al. (2018) suggested that the effects of ethnicity and geographical environment on investments are a significant part of the regional disparity in the Guangxi Zhuang Autonomous Region of China.

The determination and geo-demographical classification of language and ethnicity can be included in population studies (Burns et al., 2018, p. 418). This is not only important for investments to be made in the future and planning regarding the future but it can also be used to make inferences about the future of minorities. For example, Sapiro (2018) geo-demographically classified the population changes among the Jewish community in England and Wales using data from 2001 and 2011. The author then recommended a plan regarding minorities for the period from 
2012 to 2031. As can be seen, understanding language and dialects can help to shed light on many historical, cultural, political, and economic issues and formulate radical suggestions.

Every language is an expression of human experience on the world. The loss of each language is actually a loss of evidence to know the past of humanbeing (UNESCO, 2018). For this reason, scientific studies on the preservation of endangered languages and dialects have shown an increasing trend in the last decade. Studies conducted on languages can respond to identity confusion questions in the field of anthropology. Scientists, in particular biologists, have suggested that race is a social structure rather than a biological phenomenon. Ethnicity is based on a common heritage, language, religion, and culture (Domosh et al., 2009, p. 144, 161). Accordingly, language is one of the most important indicators of ethnicity. Answering questions such as "How did the mosaic of languages, dialects, and ethnicity emerge?" and "How is the pattern of language and ethnicity changing today?" will cast light upon many topics related to culture.

Global economic patterns give way to the assimilation of minorities and small communities, in other words, of different cultures. The most significant form of assimilation is seen as changes in languages and the dialects thereof. Transitions to dominant languages or conversion of dialects into standard languages are not explicitly enforced but rather occur because people have to leave the languages and dialects they speak behind due to various factors. Here, factors such as increased feelings of embarrassment and inferiority about the mother tongue, especially among children, unbalanced power relations between the national majority and minorities, the disadvantaged position of minorities within the country in which they live, ethnic hostilities, conflicts, and so on are likely to exert an influence (Templin et al., 2016, p. 9; UNESCO, 2018). Other factors such as natural disasters, famine and disease, globalization, migration, increased use of television and the internet, increased transportation and tourism etc. also play a role in changes and evolution in languages and dialects. The disappearance of languages and dialects and the spread of major and standard languages are directing and influencing the standardization of the world's cultural landscape. Governments, non-governmental organizations, and international organizations such as the European Union carry out various activities for the protection of languages and dialects that are rapidly disappearing (Templin et al., 2016, p. 8). Meanwhile, in the academic literature, the use of Geographic Information Systems (GISs) shows an increasing trend in efforts to preserve and record languages. 


\subsection{General Features of the Study Area and Data Source}

The study area is Eskişehir province located in western Turkey. The main Turkish constituents of Eskişehir are mainly Manavs, Yoruks, Turkmens, and Balkan immigrants. The Manavs are thought to have settled in Eskişehir between the thirteenth and fifteenth centuries. The Yoruks and Turkmens, on the other hand, moved from Yoruks to settle in the eighteenth and nineteenth centuries. External migration to Eskişehir started in the second half of the nineteenth century from the Balkans. The migration of Balkan immigrants continued until the beginning of the twentieth century. Crimean Tatars, Kazan Tatars, Noghai Tatars, Karachays, Terekemes (Karapapakhs) who emigrated from the Caucasus; Gacals, Chitaks who migrated from the Balkans, and Persians who emigrated from Iran constitute the other Turkish groups. There are also non-Turk constituents emigrated in Eskişehir. These are Pomaks, Albanians, Bosnians, Romany, and Torbeshi who emigrated from the Balkans, and Adyghes, Abkhazians, Shapsughs, Bjedughs, Besleneys, and Kabardeys who emigrated from the Caucasus. Turks who migrated from various provinces of Turkey through internal migration also settled in Eskişehir. Kurds, Zazas, and Arabs make up the non-Turkish constituents who settled in Eskişehir through internal migration. While Eskişehir procure people by letting in migrants, on the other hand, it loses people through out-migration (Boz \& Günay Aktaş, 2017). In particular, rapid migration from rural areas to urban ones causes various sociocultural problems such as the loss of dialectal characteristics (Günay Aktaş \& Boz, 2015).

\subsection{The Main Purpose and Research Questions of the Study}

This study has been conducted on some vocal tones that are not used in colloquial and standard written language but heard in rural areas today. These vocal tones are palatal $\mathrm{n} / \mathrm{y} /$, laryngeal $\mathrm{h} / \mathrm{x} /$ and open e /ä/ vocal tones. The features that were effective in choosing such vocal tones are as follows (Boz \& Günay Aktaş, 2017):

a) The palatal $n / y /$ vocal tone is a special characteristic of the Western Group Dialects of Turkey Turkish. It is mainly used by Manavs, Yoruks, and Turkmens. It is rarely used in dialects of Balkan immigrants.

b) Wheezing ha $(/ \mathrm{x} /)$ consonant is also frequent in Turkey Turkish dialects. It is a vocal tone that is frequently used by Yoruks and Turkmens, and rarely used by Manavs and Balkan immigrants.

c) The open e (/ä/) vocal tone is a characteristic feature, although it is not very common in Turkey Turkish dialects. It is often used by Balkan immigrants, but rarely used by Manavs, Turkmens and Yörüks. 
Various information from previous studies show which group use selected characteristic vocal tones (over about 100 years), and qualitative research methods were used for all of these studies (see Gemalmaz, 1978; Ercilasun, 1983; Gülensoy, 1988; Caferoğlu, 1994; Korkmaz, 1994b).

The main questions of this research are "Is the distribution of the use of characteristic vocal tones that are selected in rural settlements of Eskişehir randomized?" and "Is there any relation between the Turkish groups speaking the Oghuz dialect who settled in the rural areas of Eskişehir in different time periods?"

\subsection{Use of Geolinguistic and Geographic Information Systems in Di- alect Studies}

Geolinguistics is a new discipline (linguistic or dialect geography) that is still not considered as a part of mainstream research into human geography. Its key theme of research can be described as changes in social use and language distribution, including dialects and idiolects, with a focus on local variations arising from political and cultural differences (Gregory et al., 2009, p. 411-412). Among conventional studies, the term geolinguistics is relatively new, concentrating on the relationship between language and location. Geolinguistics does not relate to maps only, but also to cultural geography. Geolinguistics is an interdisciplinary field stemming from the combination of process, which leads to the results of language changes, and the language maps, which identify the spatial pattern of language (Hoch \& Hayes, 2010, p. 23). In comparison to geography, the spatial dimension has recently become a current concern in the social sciences. The analysis of space and place has been gaining importance in social science studies recently. Recent advancements in social sciences in conceptualization and theorization enabled notions like place and space to attract more interest among social scientists. Over the last century, the social sciences have focused on spatial thinking since people and nations have moved intensively, which, as a result, caused a deep effect on the social, economic, political, and cultural order. (Godchild, Insulin et al., 2000). For all subjects consisting of distribution in time and space, spatial thinking is a fundamental question. Most information regarding an inevitable spatial component must be spatially processed in the form of measurement, mapping, analysis, or imaging, depending on location on Earth (Teerrajanarat \& Tingsabadh, 2011a, p. 362-363). Any development on GISs and spatial statistical models provides geographers with significant advantages. Thanks to the contribution from geography and linguistics experts who worked together, validated empirical evidences were beneficial for improving dialect notions (Lee \& Kretzschmar, 1993, p. 541). The conventional approach of dialectology is subjective due to vast amount of isogloss corresponding to dozens of 
lexical variables (Grieve et al., 2011, p. 1-2). Conventional boundary maps are inaccurate, imprecise, and hence unreliable. It is also difficult to draw dialect maps using conventional methods (Teerrajanarat \& Tingsabadh, 2011, p. 56-57).

Past studies conducted on dialects mainly focused on the phonological characteristics of the language. Linguistic studies, which are a regional variation of dialectology, however, dealt with the spatial dimension of language. Linguistics deals with the syntax, vocabulary, consonants, vowels, and intonation. However, dialectologists deal with the geographical distribution of dialect characteristics (Teerrajanarat \& Tingsabadh, 2011, p. 362-363; Günay Aktaş et al. 2015).

In almost all sciences and disciplines, there is an increased demand for high-quality information in order to model the world in a realistic way and make reliable decisions. Most information includes a spatial component and requires spatial processing, such as measurement, mapping, analysis, or imaging, depending on the location. Today, researches on dialectology are increasing significantly and the multidisciplinary approach is becoming more popular. Analyses of dialects became more systematic with the integration of linguistics into other disciplines, especially geography. This multidisciplinary approach is known as geolinguistics (Jalaluddin et al., 2015, p. 70). In addition, the issue of ethnic characteristics is also being discussed in relation to the creation of good language maps (Ring, 2016).

It is very difficult to draw language/sub-dialect maps using traditional methods. As a matter of fact, dialectology has not been adequately approached with a spatial manner up to present. Data collection points have always been shown roughly and maps and cartographic representations have been, in general, hand drawn sketches on paper maps. In addition, the changes in dialects have always been recorded through overlays by comparing maps from different periods. This restriction affects the quality and accuracy of the recorded data and possibly results in unreliable maps (Teerarojanarat \& Tingsabadh, 2011, p. 363).

GISs, which emerged in the 1960's, are considered as an important tool for coping with spatial data. However, GISs have only been used in linguistics for a few decades (Teerarojanarat \& Tingsabadh 2011, p. 363). The delay in the use of GISs in linguistic applications was due to the nature of language and mapping techniques. The transitions of languages and dialects are not sharp and abrupt, but gradual. For this reason, it is very difficult to find the location of the point where a language and dialect started and ended. It is also very difficult to find which dialect is dominant in a certain area. The development 
of GISs made handling linguistics in spatial terms and representing data collection points accurately possible. Facilities for storing collected data, database management, spatial analysis, and cartographic representations are being developed increasingly.

Today, the use of GISs in dialect studies has become common in many countries. Lee and Kretschmar (1993) collected data from 1,162 people on daily vocabulary, speech, and pronunciation through surveys. They published the "Linguistic Atlas of the Middle and South Atlantic States" (LAMSAS), using the geographic database they created. Luo et al. (2000) used GISs to visualize the layout of settlements, starting with the dialects of the Tai minority groups in South China. Teerarojanarat and Tingsabadh (2008) handled 170 semantic units to illustrate changes in words in their study covering the whole Thailand. Fukushima (2010) examined a linguistic distribution pattern in a study named "Linguistic Atlas of the Five Provinces of West Japan," (LAFP) which was created using data from 1955 and 1961. He also conducted surveys in Japan's historic capital of Western Kyoto and the southern part of Japan. He examined the spread of new words from east to west and north to south. The researcher made a historical comparison and revealed that some words in the atlas changed phonologically. Teerarojanarat and Tingsabadh (2011) used GISs to create a language boundary map of Thailand based on lexical variation. They used two dialects as a reference namely, the centralized and decentralized Thai languages and used the overlay technique. Dubert (2012) ensured the preparation and mapping of a phonetic database for the Galician dialect. Maguire (2012) examined the mapping of the existing phonetic knowledge of English dialects. Methods for mapping and digitizing language data were applied in various studies.

Today, there is an increasing interest in language atlases. For example, Olariu and Olariu (2014) created an interactive database for dialects with the online Romanian Atlas. Radzi et al. (2014) aimed to better map the presentation of words and phonologies in the dialects of Northern Perak (Malaysia). Jalaluddin et al. (2015) mapped the distribution of Malay dialects using the GISs interpolation technique. They were able to show that topographic factors affect word distributions.

Although numerous studies set in Turkey have been conducted by Turkish language and literature experts, the use of GISs in language and dialect researches is very limited and new (Ercilesun, 1983; Gülensoy, 1988; Korkmaz, 1994a; Özçelik, 1997; Gülsevin, 2002; Boz, 2006). The only case where GISs have been used in language and dialect research is the study by Boz and Günay Aktaş (2017). In this study, a dialect map of Eskişehir province has been created. 


\section{Method}

Eskişehir province is a metropolitan city which is consisted of 13 district centers and 425 rural settlements. The Turkish language has various dialects. The commonly spoken dialect in Turkey is the Oghuz dialect. The residents living in 327 of the rural settlements located in the study area are Manavs, Yoruks, Turkmens, and Balkan immigrants who settled in Turkey at different times and who speak the Oghuz dialect. The data for the research were obtained from compilations made from June to September 2013 in the villages located in the rural areas of Eskişehir, where Manavs, Yoruks, Turkmens, and Balkan immigrants live. Language data were collected via face-to-face interviews. Interviews were conducted with an old resident of each village. If it was possible, the interviews were done with women since the older women are less likely to leave a village and contact people outside the village when compared to men. For this reason, older women were assumed to have protected the dialectal characteristics better. Depending on the consent of the speaker, the audio and video or audio only recordings were made. The recordings were transcribed. The palatal $\mathrm{n}(/ \mathrm{y} /)$, laryngeal $\mathrm{h}(/ \mathrm{x} /)$, and open e (/ä/) vocal tones found in a 300-word text of each village were determined. The transcriptions were checked by Turkish language dialect research specialists, and the aforementioned three characteristic vocal tone were counted to calculate their frequency.

\subsection{Data Analysis}

The audio frequencies regarding compilations were recorded in the GISs database. Spatial autocorrelation analyses and regression analyses, which are explanatory spatial statistical methods, were conducted using MapInfo 17.2 and GeoDa 1.12 software. First, an answer was sought for "Is there a spatial dependence on the use of characteristic vocal tones?" After determining the global relationship, the local spatial correlations were examined. As such, the relationships between Turkish groups speaking the Oghuz dialect who settled in rural areas in Eskişehir in different periods were analysed.

\subsection{Spatial Clustering}

Spatial statistics include statistical methods that examine the spatial distribution, similarities, clusters and relationships. Spatial statistical analysis is based on location-based methods. The most common form of spatial autocorrelation is that close values in a variable tend to cluster in observed neighboring units or regions. For this reason, the mean values for neighboring units in a map should be expected to be more similar to the values of the units selected by the purely random method. This case refers to positive spatial autocorrelation. Negative correlation is significantly different between 
neighboring regions and is indicative of the dissimilarity of neighbors (Günay Aktaş et al., 2017). The Moran's I statistic is the most well-known criterion for detecting global spatial autocorrelation. First of all, the weighted matrix must be calculated for the calculate contribution of the space. In this study "rook" contiguity-based spatial weight matrix has been used. A negative or positive Moran's I value indicates a negative or positive autocorrelation. 0 means that there is no autocorrelation, and the distribution is random.

Local indicators of spatial association (LISA) is used to determine local autocorrelation (Anselin, 1995). LISA is a method that demonstrates whether spatial clustering or outliers are meaningful for each spatial unit. LISA results are also referred to as maps. As a result of the analysis, five different groups are determined for each spatial unit. The clusters are composed of high values High-High / H-H; low values are shown as Low-Low / L-L. Because the settlements show high or low values according to their surroundings they are classified as outliers. The outliers represented as High-Low / H-L or LowHigh / L-H. The settlements which are not significant are also mentioned (Eyyüboğlu, 2015; Günay Aktaş et al., 2017). Similar high / low values $\mathrm{H}-\mathrm{H} / \mathrm{L}-\mathrm{L}$ are translated with similar high / low values and interpreted as a neighbourhood relationship.

In this study, Global Moran's I and Local Moran's I (LISA) have been used to determine global and local clusters, and to investigate spatial dependence. In these tests, the null hypothesis is that the characteristic vocal tones are randomly distributed among Eskişehir rural areas.

\subsection{Spatial Regression Analysis}

Principal target of regression analysis is to reveal the mathematical model of the relationship. In the regression analysis, spatial dependence is not taken into account when presenting the relationship model. If there is a spatial dependence on the data, in this case, it is more appropriate to use spatial regression models instead of classical regression method. The models with the spatially lagged variable are called spatial regression models. Spatial lagged variables provide spatial dependence in models as substance, in the sense that the dependent variable, which is influenced by the dependent value for other countries or error term, is influenced by the value error term for the near region. The well-known models are spatial lag model (SLM) and spatial error model (SEM) corresponding to spatially correlated dependent and error terms, respectively:

SEM is presented as follows:

$$
\begin{aligned}
& y=X \beta+u \\
& u=\lambda W u+\varepsilon, \lambda
\end{aligned}
$$


$\lambda$ is the spatial autocorrelation parameter to provide spatial dependence between error terms into the model. $\lambda$ is the spatial autocorrelation parameter to provide spatial dependence between error terms into the model. While $\varepsilon$ is distributed as normal, $\lambda$ is the spatial autocorrelation parameter to provide spatial dependence between error terms into the model. While $\varepsilon$ is distributed as normal, $\varepsilon \sim N\left(0, \sigma^{2}\right), \lambda$, is the spatial autocorrelation parameter to provide spatial dependence between error terms into the model. While $\varepsilon$ is distributed as normal, $\varepsilon \sim N\left(0, \sigma^{2}\right), u$ is thes spatial autocorrelated error term.

SLM can be expressed as follows:

$$
y=X \beta+\rho W y+\varepsilon
$$

$\rho$ is the spatial autocorrelation parameter to provide spatial dependence between the dependent variable into the model.

The null hypothesis, herein, there is no relationship between characteristic vocal tones and Oghuz dialects who migrated to rural areas of Eskişehir in different periods. For the relationship analysis, the classical regression model (OLSM) was used to determine whether the variables were significant, and the OLSM residual series used to test all assumptions were obtained. Dummy variables were used in the distribution of Turkish (Oghuz) groups by villages. Villages, are considered as 4 classes as Manavs, Yörüks Turkmens and Balkan immigrants, and is expressed dummy variable (D1, D2 and D3) (see Table 1). The Balkan immigrants were taken as the main variable.

Table 1: Definition of dummy variables

\begin{tabular}{llll}
\hline & D1 & D2 & D3 \\
\hline Manavs & 1 & 0 & 0 \\
Yoruks & 0 & 1 & 0 \\
Turkmens & 0 & 0 & 1 \\
\hline
\end{tabular}

\section{Results}

This section explores how the frequency of the use of characteristic vocal tones was distributed in the study area, whether it showed a spatial correlation or it was related to the local constituents.

\subsection{Spatial Pattern of the Characteristic Vocal Tones}

The distribution of the characteristic vocal tones is shown in Figures 1, 2, and 3. In these maps, the highest usage rate of the vocal tones is shown in red, the lower usages in yellow and then green, and the lowest usage in navy blue. The village centres where Turks are settled in Eskişehir in different time periods and differing among themselves in terms of dialect are colorized and symbolized with triangles. 
The $/ \mathrm{y} /$ vocal tone was found to be used commonly within the study area. The areas where this vocal tone is used the most are the southeast, north, and west parts of the province. The rate of use decreased in the south and northwest (see Figure 1).

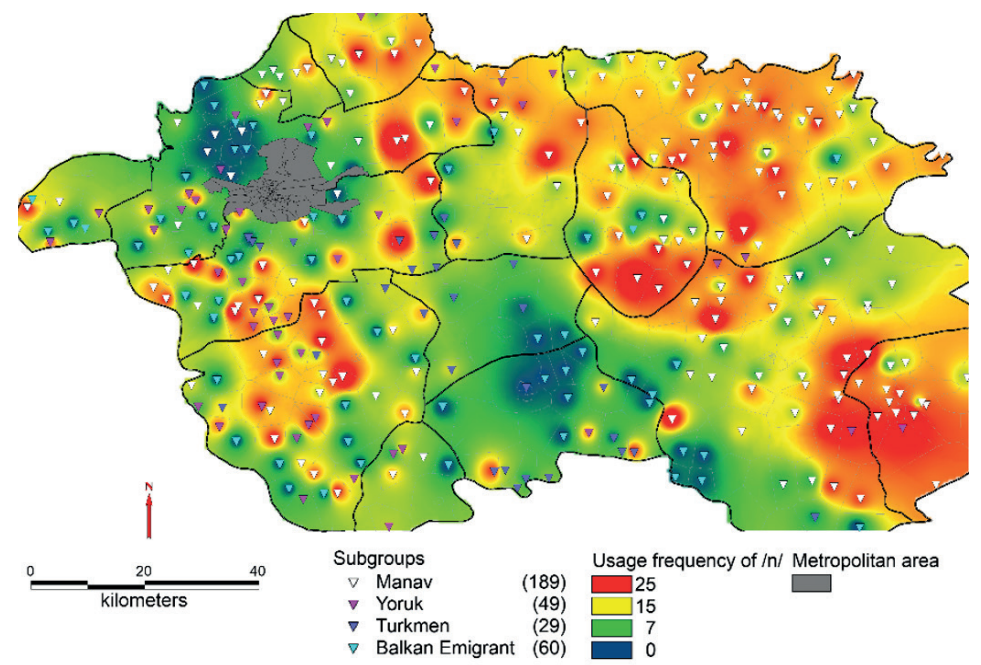

Figure 1: Distribution of the $/ \mathrm{y} /$ vocal tone in the study area

Figure 2 shows that the $/ \mathrm{x} /$ vocal tone is used commonly in the study area. The areas with the highest rate of use are located in the central part of the province, forming a discontinuous line from northwest to southeast.

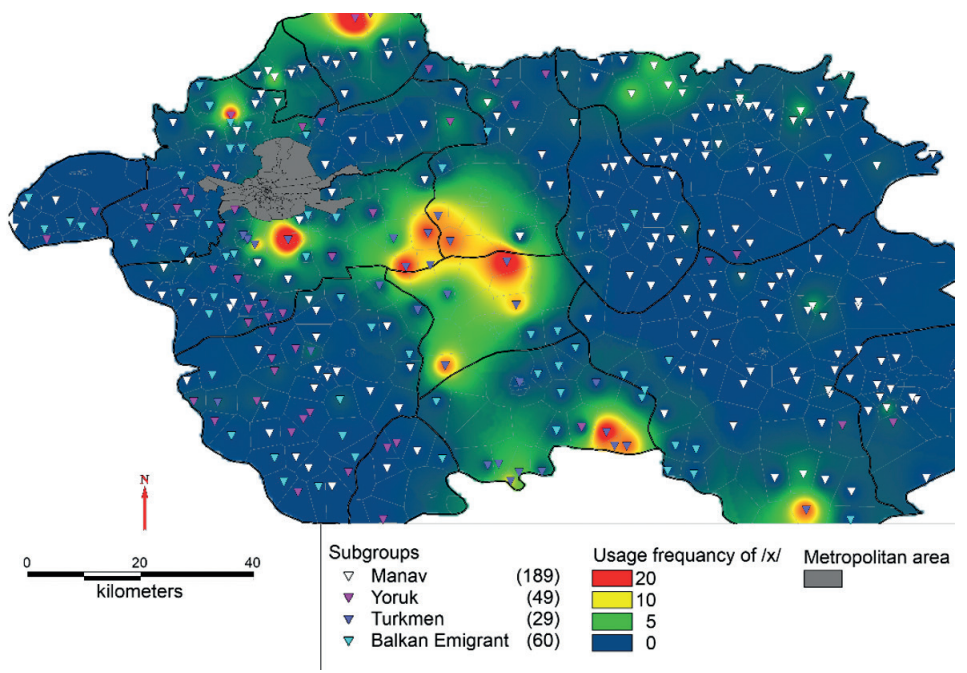

Figure 2: Distribution of the $/ \mathrm{x} /$ vocal tone in the study area 
Although the rate of use of the /ä/ vocal tone in the study area is not high, it can be understood from Figure 3 that the usage is spread throughout the province.

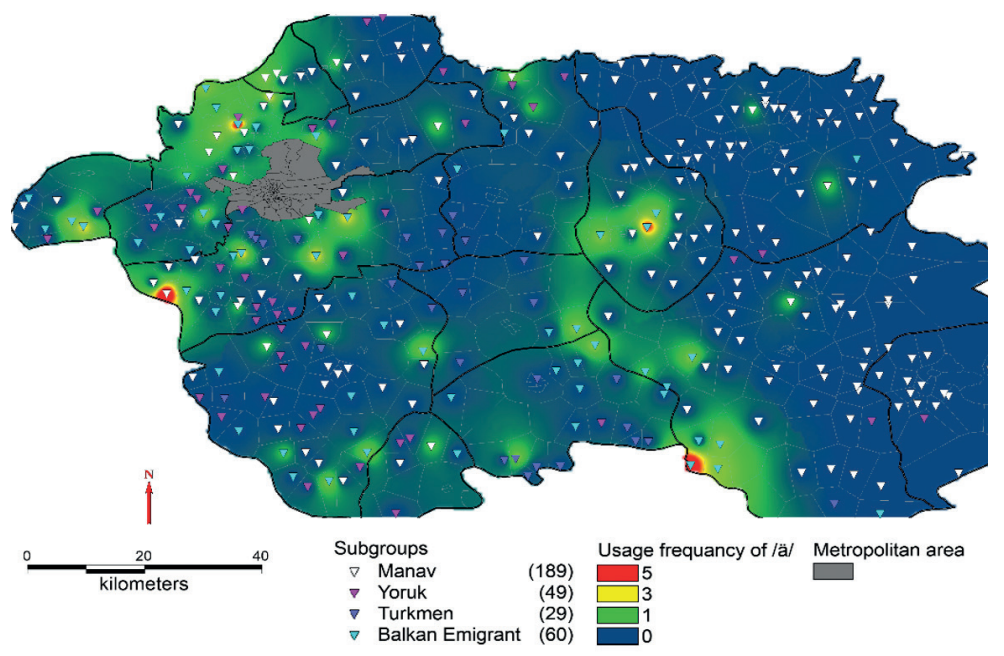

Figure 3: Distribution of the /ä/ vocal tone in the study area

\subsection{The Spatial Autocorrelations of Characteristic Vocal Tones}

Global Moran's I statistics and the related p-values of the frequency of the use of the characteristic vocal tones determined in the rural area of Eskişehir are summarized in Table 2.

Table 2: Global Moran's I value for the spatial autocorrelations of characteristic vocal tones

\begin{tabular}{cccc}
\hline & Moran's I value & Z scores & p-values \\
\hline$/ \mathrm{y} /$ vocal tone & 0.1634 & 5.1971 & 0.001 \\
\hline$/ \mathrm{x} /$ vocal tone & 0.1905 & 6.3930 & 0.001 \\
\hline /ä/ vocal tone & 0.0333 & 1.2094 & 0.116 \\
\hline
\end{tabular}

It is observed from Table 2 that while $/ \mathrm{y} /$ vocal tone and $/ \mathrm{x} /$ vocal tone show global positive spatial correlation, /ä/ vocal tone is distributed randomly over the whole region. To identify local clusters and local spatial outliers, the most common measure of local spatial autocorrelation is collectively known as local indicators of spatial association (LISA). Now, LISA has been considered to detect local clusters in terms of $/ \mathrm{y} /, \mathrm{x} / \mathrm{and} / \ddot{\mathrm{a}} /$ vocal tones. LISA is also proportionate to the (global) value of the Moran's statistic. Through LISA tests, the following values in Table 3 are then tabulated. 
Table 3: Significant LISA at 5\% pseudo-significance for characteristic vocal tones

\begin{tabular}{|c|c|c|c|}
\hline Spatial typology for $/ \mathrm{y} /$ vocal tone & & $\mathrm{n}$ & $\%$ \\
\hline \multirow{3}{*}{ Clusters $(+)$ assoc. } & Not significant & 265 & 0.8104 \\
\hline & $\mathrm{H}-\mathrm{H}^{*}$ & 20 & 0.0612 \\
\hline & $\mathrm{L}-\mathrm{L} * *$ & 23 & 0.0703 \\
\hline \multirow[t]{2}{*}{ Outliers (-) assoc. } & $\mathrm{L}-\mathrm{H}$ & 10 & 0.0306 \\
\hline & $\mathrm{H}-\mathrm{L}$ & 9 & 0.0275 \\
\hline \multirow[t]{2}{*}{ Spatial typology for / $\mathrm{x} /$ vocal tone } & & $\mathrm{n}$ & $\%$ \\
\hline & Not significant & 297 & 0.9083 \\
\hline \multirow[t]{2}{*}{ Clusters $(+)$ assoc. } & $\mathrm{H}-\mathrm{H}^{*}$ & 13 & 0.0398 \\
\hline & $\mathrm{L}-\mathrm{L} * *$ & 0 & 0.0000 \\
\hline \multirow[t]{2}{*}{ Outliers (-) assoc. } & $\mathrm{L}-\mathrm{H}$ & 14 & 0.0428 \\
\hline & $\mathrm{H}-\mathrm{L}$ & 3 & 0.0092 \\
\hline \multirow[t]{2}{*}{ Spatial typology for /ä/ vocal tone } & & $\mathrm{n}$ & $\%$ \\
\hline & Not significant & 286 & 0.8746 \\
\hline \multirow[t]{2}{*}{ Clusters (+) assoc. } & $\mathrm{H}-\mathrm{H}^{*}$ & 4 & 0.0122 \\
\hline & $\mathrm{L}-\mathrm{L}^{* *}$ & 0 & 0.0000 \\
\hline \multirow[t]{2}{*}{ Outliers (-) assoc. } & $\mathrm{L}-\mathrm{H}$ & 15 & 0.0459 \\
\hline & H-L & 22 & 0.0673 \\
\hline
\end{tabular}

*hot spots $* *$ cold spots

The results shown in Table 3 also support the results in Table 2. There are many positive spatial clusters for $/ \mathrm{y} /$ vocal tone $(20 \mathrm{H}-\mathrm{H}$ related villages $)$ and $/ \mathrm{x}$ / vocal tone (13 $\mathrm{H}-\mathrm{H}$ related villages). In contrast, there is very little positive clustering for /ä/ vocal tone (4 H-H related villages). /ä/ vocal tone presents mostly H-L and L-H clusters. This refers to the dissimilarity or outlier cases. The positive spatial clustering for /ä/ vocal tone is negligible.

\subsection{Relationship between characteristic vocal tones and Turkish groups speaking Oghuz dialect}

The relationship between $/ \mathrm{y} /, / \mathrm{x} /$ and $/ \mathrm{a} /$ vocal tones and Turkish groups speaking Oghuz dialect who settled in Eskişehir in different periods has been examined by classical linear regression and spatial regression models (see Table 4, 5 and 6). As a result of these tests, it can be said that the errors have fluctuating variance and do not have a normal distribution. The distortion of these assumptions may be due to spatial dependence. Under these circumstan- 
ces, it is concluded that OLSM is not suitable. As a result, there is sufficient evidence for the transition to spatial regression models. Table 4 shows the differences in the use of $/ \mathrm{y} /$ vocal tone among Turkish groups speaking Oghuz dialect.

Table 4: Estimates of the parameters of OLSM, SLM and SEM for $/ \mathrm{y} /$

\begin{tabular}{|c|c|c|c|c|c|c|c|c|}
\hline & & Coefficient & Std.Error & $\mathrm{t}$-Statistic & $\mathrm{p}$-value & $\mathrm{R}^{2}$ & AIC & SIC \\
\hline \multirow{4}{*}{ OLSM } & $\mathrm{C}$ & 0.53333 & 0.982721 & 0.54271 & 0.5877 & \multirow{4}{*}{0.440} & \multirow{4}{*}{2259.41} & \multirow{4}{*}{2274.57} \\
\hline & D1 & 17.5831 & 1.12797 & 15.5882 & 0.0000 & & & \\
\hline & D2 & 16.5708 & 1.47408 & 11.2415 & 0.0000 & & & \\
\hline & D3 & 9.86667 & 1.70212 & 5.79668 & 0.0000 & & & \\
\hline & & 0.16572 & 0.06873 & 2.41112 & 0.01590 & \multirow{5}{*}{0.455} & \multirow{5}{*}{2255.99} & \multirow{5}{*}{2274.94} \\
\hline & $\mathrm{C}$ & -1.3561 & 1.23842 & -1.0950 & 0.27349 & & & \\
\hline \multirow[b]{3}{*}{ SLM } & D1 & 16.8751 & 1.15357 & 14.6285 & 0.00000 & & & \\
\hline & D2 & 16.1841 & 1.45682 & 11.1092 & 0.00000 & & & \\
\hline & D3 & 9.89207 & 1.67601 & 5.90216 & 0.00000 & & & \\
\hline \multirow{5}{*}{ SEM } & & 0.18361 & 0.085451 & 2.14881 & 0.03165 & \multirow{5}{*}{0.454} & \multirow{5}{*}{2255.25} & \multirow{5}{*}{2270.41} \\
\hline & $\mathrm{C}$ & 0.74414 & 1.02779 & 0.72401 & 0.46905 & & & \\
\hline & D1 & 17.3658 & 1.15122 & 15.0847 & 0.00000 & & & \\
\hline & D2 & 16.2255 & 1.47034 & 11.0352 & 0.00000 & & & \\
\hline & D3 & 9.38204 & 1.77918 & 5.27324 & 0.00000 & & & \\
\hline
\end{tabular}

The OLSM model estimation is $Y=0.533333+17.5831 D 1+16.5708 D 2+$ 9.86667D3. $\mathrm{H}_{0}: \mathrm{C}=0$ is not rejected. That is to say, $/ \mathrm{y} / \mathrm{vocal}$ tone is not meaningful for the Balkan immigrants. On the other hand, Manavs, Yoruks, Turkmens use /n/ vocal tone more than the Balkan immigrants. Since the D1, D2 and D3 are significant, it can be said that these three groups use /y/ vocal tone at the different levels. In other words, it can be said that the expected frequency of / $\mathrm{n} /$ vocal tone is different for these groups. The SLM model has been estimated as $\mathrm{Y}=-1.35614+16.8751 \mathrm{D} 1+16.1841 \mathrm{D} 2+9.89207 \mathrm{D} 3$ $+0.165728 Y$. This vocal tone is most used by Manavs. In the second place, it is used by Yoruks. The SEM model is equal to $\mathrm{Y}=0.744141+17.3658 \mathrm{D} 1$ $+16.2255 \mathrm{D} 2+9.38204 \mathrm{D} 3$. The significant autocorrelation coefficient of the error in terms of the SEM model is 0.165728 . The additional coefficients $(\lambda$ and $\rho$ ) in these models show spatial dependence. When the $p$-value $<0.05$ these coefficients are significant. This means that there is a spatial dependence for $/ \mathrm{y} /$ vocal tone. At the spatial models larger R2 and smaller AIC and SIC criteria which are calculated points to the superiority of spatial models. Table 
5 shows whether the differences in the use of / $\mathrm{x}$ / vocal tone among the Turkish groups speaking Oghuz dialect.

Table 5: Estimates of the parameters of OLSM, SLM and SEM for $/ \mathrm{x} /$ vocal tone

\begin{tabular}{|c|c|c|c|c|c|c|c|c|}
\hline & & Coefficient & Std.Error & $\mathrm{t}$-Statistic & $\mathrm{p}$-value & $\mathrm{R}^{2}$ & AIC & SIC \\
\hline \multirow{4}{*}{ OLSM } & $\mathrm{C}$ & 0.01666 & 0.547922 & 0.03041 & 0.97577 & \multirow{4}{*}{0.3082} & \multirow{4}{*}{1877.35} & \multirow{4}{*}{1892.51} \\
\hline & D1 & 0.36428 & 0.628909 & 0.57923 & 0.56284 & & & \\
\hline & D2 & 1.8375 & 0.821883 & 2.23572 & 0.02605 & & & \\
\hline & D3 & 10.0833 & 0.949029 & 10.6249 & 0.00000 & & & \\
\hline \multirow[b]{2}{*}{$\rho$} & & 0.13102 & 0.077800 & 1.68411 & 0.09216 & \multirow{5}{*}{0.3157} & \multirow{5}{*}{1876.78} & \multirow{5}{*}{1895.73} \\
\hline & $\mathrm{C}$ & -0.1243 & 0.554942 & -0.2241 & 0.82267 & & & \\
\hline \multirow{3}{*}{ SLM } & D1 & 0.38738 & 0.625381 & 0.61943 & 0.53563 & & & \\
\hline & D2 & 1.88038 & 0.812634 & 2.31394 & 0.02067 & & & \\
\hline & D3 & 9.46459 & 1.00049 & 9.45997 & 0.00000 & & & \\
\hline \multirow{5}{*}{ SEM } & & 0.14419 & 0.087152 & 1.65448 & 0.09803 & \multirow{5}{*}{0.3160} & \multirow{5}{*}{1874.84} & \multirow{5}{*}{1890} \\
\hline & $\mathrm{C}$ & 0.14003 & 0.567059 & 0.24694 & 0.80495 & & & \\
\hline & D1 & 0.182318 & 0.639653 & 0.28502 & 0.77562 & & & \\
\hline & D2 & 1.88211 & 0.821043 & 2.29234 & 0.02189 & & & \\
\hline & D3 & 9.90791 & 0.983035 & 10.0789 & 0.00000 & & & \\
\hline
\end{tabular}

OLSM, SLM and SEM for $/ \mathrm{x} /$ are significant for Yoruks and Turkmens. However, it is not significant for Manavs and Balkan immigrants. OLS model is equal $\mathrm{Y}=0.016666+0.364286 \mathrm{D} 1+1.8375 \mathrm{D} 2+10.0833 \mathrm{D} 3$.

Hypotheses $\mathrm{H}_{0}: \mathrm{C}=0$ and $\mathrm{H}_{0}: \mathrm{D} 1=0$ are accepted. That is, the basic variable which is Balkan immigrants and Manavs is not significant. Yoruks and Turkmens variables are significant. Table 3 shows respectively the spatial models of SLM and SEM. In addition to the results of the OLSM model, the spatial coefficients $\lambda$ and $\rho$ are not significant in these models.

$$
\begin{aligned}
& Y=0.131025 \mathrm{WY}-0.12436+0.387384 \mathrm{D} 1+1.88038 \mathrm{D} 2+9.46459 \mathrm{D} 3 \\
& Y=0.140031+0.1400 \mathrm{D} 1+1.8821 \mathrm{D} 2+9.9079 \mathrm{D} 3
\end{aligned}
$$

Similar results have been obtained at all models. The variables of Yoruks and Turkmens usage frequencies of $/ \mathrm{x} /$ vocal tone are significant. Because of the parameter, values of Yoruks and Turkmens have been estimated high, usage of $/ \mathrm{x} /$ vocal tone of Turkmens is more than Balkan immigrants. Table 6 shows the usage differences /ä/ vocal tone among the Turkish groups speaking Oghuz dialect. 
Table 6: Estimates of the parameters of OLSM, SLM and SEM for /ä/ vocal tone

\begin{tabular}{|c|c|c|c|c|c|c|c|c|}
\hline & & Coefficient & Std. Error & $\mathrm{t}-$ Statistic & $\mathrm{p}$-value & $\mathrm{R}^{2}$ & AIC & SIC \\
\hline \multirow{4}{*}{ OLSM } & $\mathrm{C}$ & 1.06667 & 0.118343 & 9.01336 & 0.00000 & \multirow{4}{*}{0.1384} & \multirow{4}{*}{875.065} & \multirow{4}{*}{890.225} \\
\hline & D1 & -0.9079 & 0.135835 & -6.6841 & 0.00000 & & & \\
\hline & D2 & -1.0458 & 0.177514 & -5.8915 & 0.00000 & & & \\
\hline & D3 & -0.9333 & 0.204976 & -4.5533 & 0.00001 & & & \\
\hline \multirow{5}{*}{ SLM } & & 0.02561 & 0.08732 & 0.29331 & 0.76928 & \multirow{5}{*}{0.1387} & \multirow{5}{*}{876.985} & \multirow{5}{*}{895.935} \\
\hline & $\mathrm{C}$ & 1.05598 & 0.122817 & 8.59798 & 0.00000 & & & \\
\hline & D1 & -0.9024 & 0.135619 & -6.6543 & 0.00000 & & & \\
\hline & D2 & -1.0423 & 0.176542 & -5.9044 & 0.00000 & & & \\
\hline & D3 & -0.9320 & 0.20385 & -4.5720 & 0.00000 & & & \\
\hline \multirow{5}{*}{ SEM } & & -0.0061 & 0.09255 & -0.0669 & 0.94663 & \multirow{5}{*}{0.1384} & \multirow{5}{*}{875.061} & \multirow{5}{*}{890.221} \\
\hline & $\mathrm{C}$ & 1.06713 & 0.1174 & 9.08972 & 0.00000 & & & \\
\hline & D1 & -0.90887 & 0.134822 & -6.7413 & 0.00000 & & & \\
\hline & D2 & -1.0465 & 0.176325 & -5.9352 & 0.00000 & & & \\
\hline & D3 & -0.9332 & 0.203304 & -4.5902 & 0.00000 & & & \\
\hline
\end{tabular}

The estimated OLSM, SLM, and SEM value are expressed below for the /ä/ vocal tone usage.

$$
\begin{aligned}
& Y=1.06667+-0.90793 \mathrm{D} 1-1.04583 D 2-0.93333 D 3 \\
& Y=0.025613 W Y+1.05598 D 1+-0.90244 D 2-1.04237 D 3-0.932 D 4 \\
& Y=1.06713-0.90887 D 1-1.04653 D 2-0.93322 D 3
\end{aligned}
$$

The whole model is significant in terms of the usage of /ä/ vocal tone for the Manavs, Yoruks, Turkmens and Balkan immigrants variables $(p<0.05)$. The whole model results show that /ä/ vocal tone usage is more among the Balkan immigrants than other Turkish groups speaking Oghuz dialect. The negative coefficients result show that /ä/ vocal tone usage is decreasing among other variables such as Manavs, Yoruks and Turkmens. On the other hand, spatial autocorrelation coefficients $(\lambda$ and $\rho)$ has not been significant in spatial models $(\mathrm{p}>0.05)$. $\mathrm{R}^{2}$, AIC and SIC are found similar for the OLSM and SLM and SEM. It can be said that OLSM is suitable model for the /ä/ vocal tone.

\section{Discussion}

Spoken languages and dialects play a key role in understanding ethnic groups. A language is a strong indicator of ethnic identification. A dialect is a useful tool for identifying ethnic groups because it is a suitable, accessible, observable, and objective symbol of groups. Mapping the linguistic appearance in multicultural countries like Turkey is a complex and interesting field of study (Suwilai \& Naraset, 1996). Turkey has hosted many civilizations throughout 
its history due to its geopolitical location between Asia and Europe. This resulted in numerous local languages and dialects being spoken in Turkey. Turkish has various dialects, the most being the Oghuz dialect. However, there are also dialectal differences among the groups using this dialect. In the study area of Eskişehir, the Oghuz dialect is spoken by Manavs, Yoruks, Turkmens, and Balkan immigrants. For this reason, Eskişehir province was nominated as the study area.

Languages and dialects are the most concrete reflections of the human mosaic in a place. However, today, dialects are rapidly disappearing due to globalization, the increased use of television and the Internet, increased transportation facilities, tourism, etc. Dialects are cultural identities and each group has its own way of speaking. Until recently, carrying out realistic modelling and inventory-taking of human heritage like language as a significant cultural element was very difficult. Today, GISs are an important tool in coping with spatial data. The use of GISs in language and dialect research is quite new. They have been used in a variety of studies, particularly to demonstrate the distribution of languages (Lee \& Kretschmar, 1993; Teerarojanarat \& Tingsabadh, 2011; Radzi et al., 2014; Jalaluddin et al., 2015). None of these studies, however, examined their correlation with different variables using spatial autocorrelation and regression analyzes.

In this study, the results of spatial autocorrelation of characteristic vocal tones revealed that $/ \mathrm{y} /$ vocal tone and $/ \mathrm{x} /$ vocal tone show global positive spatial correlation, while spatial clustering is insignificant for /ä/ vocal tones. This situation may be due to the small number of immigrant villages and their dispersed settlement within the boundaries of the city. In this study, whether a relation exists between Turkish groups speaking Oghuz dialect who settled in Eskişehir in different time periods is investigated based on the use of $/ \mathrm{y} /, \mathrm{x} /$ and /ä/ vocal tones.

- $\quad / \mathrm{y} /$ vocal tone is used by Manavs, Yoruks, and Turkmens. It is understood that these groups also use $/ \mathrm{y} /$ vocal tone with different frequencies. This vocal tone is mostly used by Manavs, followed by Yörüks and Turkmens.

- The use / $\mathrm{x} /$ vocal tone is significant for Yörüks and Turkmens. It is found out that Turkmens use $/ \mathrm{x} /$ vocal tone quite often compared to Yörüks.

- $\quad / a ̈ /$ vocal tone is used by Balkan immigrants.

These results conform with the outcomes of studies that have being conducted since commencement of Turkish dialect researches (for almost a century). None of the former studies has employed quantitative research 
methods (see Caferoglu, 1994; Gemalmaz, 1978; Gülensoy, 1988; Korkmaz, 1994; Ercilasun, 1983).

The language and dialect spoken have a key role in understanding ethnic groups. The language is a strong indicator of ethnic identification. The dialect is a useful tool for identifying ethnic groups because it is a suitable, accessible, observable and objective symbol of groups (Suwilai \& Naraset, 1996, p. 79). The findings of the research suggest that the dialect features can also be used in understanding sub-dialects within the same ethnic group. Hence, this is a pioneering study in terms of the methods used.

Turkey has quite a dynamic population structure. Also, due to the fact that it is a rapidly developing country integrated with the world and faces factors such as globalization, it has become a country where the dialect diversity is gradually decreasing. Dialects, like languages, constitute a significant part of people's identity, ethnicity, and culture. It is recognized by all governments that languages and dialects need to be preserved. However, doing this is still complex (UNESCO, 2018). GISs will be a powerful tool in language research, as they allow integrated analyses of attributes and graphical data.

The widespread use of databases with graphical and attribute information on languages and dialects in the context of local governments will be one of the most concrete steps taken in this regard. The extensification of inventory studies integrated with GISs will make significant contributions to preservation and planning studies in monitoring the temporal and spatial changes of languages and dialects. In addition, as seen from the findings obtained through the spatial statistical methods applied in this study, it is thought that GISs will make important contributions to explaining the complex spatial structures of languages. For this reason, the widespread use of GISs in the geolinguistic field will make significant contributions to the preservation and recording of language, which is one of the most important elements of cultural heritage.

Indeed, the spatial distribution and changes of languages and ethnicities are important factors when it comes to answering questions in many fields such as history, culture, economics, etc. Thus, the widespread use of GISs in geolinguistics and spatial statistical methods will be effective in testing many hypotheses in dialect studies. This study also revealed that spatial statistical methods can be used in relation to changes in the sub-versions of a dialect. This study further provided scientists who conduct studies on geolinguistics and dialectology with a new point of view based on quantitative research methods. 
Similar to a previous project (Boz, E., Bozkurt, F., \& Doğru, F., 2018), we are planning to conduct a corpus-based research on Manavs, Yoruks, Turkmens, and Balkan immigrants.

\section{Conclusion}

In this study, spatial autocorrelation or spatial regression methods were used to answer the following questions: "Is there any autocorrelation in the distribution of the use of the mentioned characteristic vocal tones in rural settlements of Eskişehir? Is there any relation between groups who settled in rural areas of Eskişehir in different time periods, in terms of using such vocal tones?". The results obtained from numerous studies that have been ever conducted using qualitative research methods were achieved using quantitative research methods. Therefore, this is a pioneering study in terms of the use of spatial statistical methods in relation with language and dialect characteristics. The correlations determined by spatial statistics will be guiding to obtain objective and reproducible results in geolinguistic studies. The method applied has an innovative perspective on language researches. The use of spatial statistical methods in dialect researches will contribute to the literature and application studies.

This method which is used with the vocal tones for Turkish, a head-final language, can also be used for head-initial, radical, or inflected languages.

\section{Compliance with Ethical Standards:}

This research was funded by TÜBİTAK (Project No: 112K405).

\section{References}

Anselin, L. (1995). Local indicators of spatial association- LISA. Geographical Analysis, 27(2), 93-115.

Bent, T., Atag1, E., Akbik , A., \& Bonifield, E. (2016). Classification of regional dialects, international dialects, and nonnative accents. Journal of Phonetics, 58, 104-117. doi:https://doi.org/10.1016/j.wocn.2016.08.004.

Boz, E. (2006). Afyonkarahisar merkez ağzı (Dialect of Afyonkarahisar province center). Ankara: Gazi Kitabevi.

Boz, E. \& Günay Aktaş, S. (2017). Eskişehir ili dil atlası (Language atlas of Eskişehir province). Ankara: Gazi Kitabevi.

Boz, E., Bozkurt, F. \& Doğru, F. (2018). Corpus-based research on terminology of Turkish Lexicography (CBRT-TURKLEX). Lexikos, 28, 428-439.

Burns, L., See, L., Heppenstall, A. \& Birkin, M. (2018). Developing an individual-level geodemographic classification. Appl. Spatial Analysis, 11, 417-437. doi:10.1007/s12061-017-9233-7. 
Caferoğlu, A. (1994). Anadolu dialektolojisi üzerine malzeme (Materials on Anatolian dialectology). Ankara: Türk Coğrafya Kurumu.

Dai, Q., Ye, X., Wei, Y. D., Ning, Y. \& Dai, S. (2018). Geography, ethnicity and regional inequality in Guangxi Zhuang Autonomous Region, China. Applied Spatial Analysis and Policy, 11, 557-580. doi:10.1007/s12061-017-9229-3.

Domosh, M., Neunmann, R., Price, P. \& Jordan-Bychkov, T. (2009). The Human mosaic: A cultural approach to human geography. New York: W. H. Freeman and Company.

Dubert, F. (2012). Developing a database for dialectometric studies: The ALGa phonetic data. Dialectometrical analysis of 230 working maps. International Society for Dialectology and Geolinguistics, 19(1), 23-61. doi:10.1515/ dig.2011.002.

Ercilasun, A. B. (1983). Kars ili ăgızlarl: Ses bilgisi (Dialects of Kars province: Phonetics). Ankara: Gazi Üniversitesi.

Eyyuboğlu, B. B. (2015). Sosyal bilimlerde mekânsal istatistik ve coğrafi bilgi sistemleri: kuramdan uygulamaya (Spatial statistics and geographic information systems in social sciences: From theory to application). Doctoral Dissertation, Eskisehir: Anadolu University, The Graduate School of Sciences.

Fukushima, C. (2010). Comparing linguistic maps from different surveys. Dialectologia, 4, 13-22.

Gemalmaz, E. (1978). Erzurum ili ăğzları (Dialects of Erzurum province). Ankara: Türk Dil Kurumu.

Goodchild, M. F., Anselin, L., Appelbaum, R. P. \& Harthorn, B. H. (2000). Toward spatially integrated social science. International Regional Science Review, 23(2), 139-159.

Gregory, D., Haggett, P., Smith, D. M. \& Stoddart, D. R. (2009). The dictionary of human geography. Singapore: Willey-Bleckwell.

Grieve, J. (2011). The use of spatial outocorrelation statistics for the analysis of regional linguistic variation. Retrieved from: http://edoc.hu-berlin.de/conferences/qitl-4/ grieve-jack-34/PDF/grieve.pdf.

Gülensoy, T. (1988). Kütahya ve yöresi ağızları (Dialect of Kütahya province and its vicinity). Ankara: Türk Dil Kurumu.

Gülsevin, G. (2002). Uşak ili ağızları (Uşak province dialects). Ankara: Türk Dil Kurumu.

Günay Aktaş, S. \& Boz, E. (2015). Süt parası karşılığında Eskişehir'e gelin göçü (Bride migration to Eskişehir in exchange for the money of breast milk). Uluslararast Sosyal Araştırmalar Dergisi (The Journal of International Social Research), 8(40), 476-485.

Günay Aktaş, S., Boz, E. \& İlbaş, S. (2015). Geolinguistics: A case of Balkan immigrant dialect maps in Eskişehir. Anadolu Üniversitesi Sosyal Bilimler Dergisi (Anadolu University Journal of Social Sciences), 15(4), 1-6. 
Günay Aktaş, S., Genç Kumtepe, E., Mert Kantar, Y., Ulukan, I. C., Aydın, S., Aksoy, T. \& Er, F. (2017). Improving gender equality in higher education in Turkey. Applied Spatial Analysis and Policy, 12, 167-189. doi:10.1007/s12061017-9235-5.

Hoch, S., \& Hayes, J. J. (2010). Geolinguistics: The incorporation of geographic information systems and science. The Geographical Bulletin, 51, 23-36.

Jalaluddin, N. H., Ahmad, Z., Radzi, H., \& Omar, M. (2015). Lexicon variation and distribution of Malay dialect in Perak: A GIS approach. Iman, 3(3), 69-77. doi:10.17576/IMAN-2015-0303-07.

Korkmaz, Z. (1994a). Bartın ve yöresi ăgıları (Dialect of Bartın province and its vicinity). Ankara: Türk Dil Kurumu.

Korkmaz, Z. (1994b). Nevşehir ve yöresi ağızlar (Dialect of Nevşehir province and its vicinity). Ankara: Türk Dil Kurumu.

Lee, J., \& Kretzschmar, W. A. (1993). Spatial analysis of linguistic data with GIS functions. International Journal of Geographical Information Science, 7(6), 541-560.

Luo, W., Hartmann, J., Li, J. \& Sysamouth, V. (2000). GIS mapping and analysis of Tai linguistic and settlement patterns in Southern China. International Journal of Geographic Information Sciences, 6(2), 129-136.

Maguire, W. (2012). Mapping the existing phonology of English dialects. Journal of the International Society for Dialectology and Geolinguistics, 20(1), 84107. doi:10.1515/dialect-2012-0006.

Olariu, F. T. \& Olariu, V. (2014). The Romanian linguistic cartography in the digitizing era: the electronic atlases. Journal of the International Society for Dialectology and Geolinguistics, 22(1), 75-90. doi:10.1515/dialect-2014-0005.

Özçelik, S. (1997). Urfa merkez ă̆zı (Dialect of Urfa province center). Ankara: Türk Dil Kurumu.

Radzi, H., Jalaluddin, N. H., Ahmad, Z., Hamzah, S. N., Yusoff, Y. M., \& Sanit, N. (2014). Geo-linguistics study on lexical and phonology dialect variations in North Perak, Malaysia. Procedia - Social and Behavioral Sciences, 118, 152-158.

Ring, H. (2016). Mapmaking for language documentation and description. Language Documentation \& Conservation, 10, 188-242.

Sapiro, P. (2018). Back to the future: Applying a current geodemographic classification to historic data to produce trend-based population projections. Appl. Spatial Analysis, 11, 121-146. doi:10.1007/s12061-016-9209-z.

Suwilai, P. \& Naraset, P. (1996). Language and ethnicity on the Korat Plateau. Thailand: Institute of Language and Culture for Rural Development. http://hdl. handle.net/2433/187673.

Teerarojanarat, S. \& Tingsabadh, K. (2008). A GIS-based approach for dialect boundary studies. Dialectologia, 6, 55-75. 
Teerarojanarat, T. \& Tingsabadh, K. (2011). Using GIS for linguistic study: a case of dialect change in the Northeastern Region of Thailand. Procedia Social and Behavioral Sciences, 21, 362-371.

Templin, T., Seidl, A., Wickström, B., \& Feichting, G. (2016). Optimal language policy for the preservation of a minority language. Mathematical Social Sciences, 81, 8-21.

Tunçel, H. (2000). Türkiye'de ismi değiştirilen köyler (Renamed villages in Turkey). Firat Üniversitesi Sosyal Bilimler Dergisi (Firat University Journal of Social Science), 10(2), 23-34.

UNESCO. (2018). Topic: Protection and preservation of originary languages and dialects in a globalized world. $11 \mathrm{Kasim} 2018$ tarihinde https://upaep.mx/micrositios/upamun/unesco.pdf. 


\section{Extended Summary}

Geolinguistics is an interdisciplinary field stemming from the combination of process, which leads to the results of language changes, and the language maps, which identify the spatial pattern of language (Hoch \& Hayes, 2010, p. 23). It's key theme of research can be described as changes in social use and language distribution, including dialects and idiolects, with a focus on local variations arising from political and cultural differences (Gregory et al., 2009, p. 411-412). Among conventional studies, the term geolinguistics is relatively new, concentrating on the relationship between language and location. Geolinguistics does not only relate to maps, but also to cultural geography.

For all subjects consisting of distribution in time and space, spatial thinking is a fundamental question. Most information regarding an inevitable spatial component must be spatially processed in the form of measurement, mapping, analysis, or imaging, depending on location on Earth (Teerrajanarat \& Tingsabadh, 2011a, p. 362363). Any development on GISs and spatial statistical models provides geographers with significant advantages. Thanks to the contribution from geography and linguistics experts who worked together, validated empirical evidences were beneficial for improving dialect notions (Lee \& Kretzschmar, 1993, p. 541). The conventional approach of dialectology is subjective due to vast amount of isogloss corresponding to dozens of lexical variables (Grieve et al., 2011, p. 1-2). Conventional boundary maps are inaccurate, imprecise, and hence unreliable. It is also difficult to draw dialect maps using conventional methods (Teerrajanarat \& Tingsabadh, 2011, p. 56-57). Past studies conducted on dialects mainly focused on the phonological characteristics of the language. Linguistic studies, which are a regional variation of dialectology, however, dealt with the spatial dimension of language. Linguistics deals with the syntax, vocabulary, consonants, vowels, and intonation. However, dialectologists deal with the geographical distribution of dialectal characteristics (Teerrajanarat \& Tingsabadh, 2011, p. 362-363; Günay Aktaş et al., 2015). Today, research on dialectology is increasing significantly and the multidisciplinary approach is becoming more popular. Analyses of dialects became more systematic with the integration of linguistics into other disciplines, especially geography. In addition, the issue of ethnic characteristics is also being discussed in relation to the creation of good language maps (Ring, 2016).

The main questions of this research are "Is the distribution of the use of characteristic vocal tones that are selected in rural settlements of Eskişehir randomized?" and "Is there any relation between the Turkish groups speaking the Oghuz dialect who settled in the rural areas of Eskişehir in different time periods?". This study has been conducted on some vocal tones that are not used in colloquial and standard written language but heard in rural areas today. These vocal tones are palatal $n / \mathrm{y} /$, laryngeal $\mathrm{h} / \mathrm{x} /$ and open e /ä/ vocal tones.

Various information from previous studies show which constituents use selected characteristic vocal tones (over about 100 years), and qualitative research methods were used for all of these studies (Gemalmaz, 1978; Ercilasun, 1983; Gülensoy, 1988; Caferoğlu, 1994; Korkmaz, 1994b). Although numerous studies set in Turkey 
have been conducted by Turkish language and literature experts, the use of a GIS in language and dialect research is very limited and new (Ercilasun, 1983; Gülensoy, 1988; Korkmaz, 1994a; Özçelik, 1997; Gülsevin, 2002; Boz, 2006). The only case of a GIS being used in language and dialect research is the study by Boz and Günay Aktaş (2017). In this study, a dialect map of Eskişehir province has been created.

The data for the research were obtained from compilations made from June to September 2013 in the villages located in the rural areas of Eskişehir, where Manavs, Yoruks, Turkmens, and Balkan immigrants live. Language data were collected through face-to-face interviews. Depending on the consent of the speaker, the audio and video or audio only recordings were made. The recordings were transcribed. The palatal $\mathrm{n}(/ \mathrm{y} /)$, laryngeal $\mathrm{h}(/ \mathrm{x} /)$, and open e $(/ \mathrm{a} /)$ vocal tones found in the 300 -word text of each village were determined. The transcriptions were checked by Turkish language dialect research specialists, and the aforementioned three characteristic vocal tone were counted to calculate their frequency. The audio frequencies regarding compilations were recorded in the GIS database. Spatial autocorrelation analyses and regression analyses, which are explanatory spatial statistical methods, were conducted using MapInfo 17.2 and GeoDa 1.12 software.

In this study, the results of spatial autocorrelation of characteristic vocal tones revealed that $/ \mathrm{y} /$ vocal tone and $/ \mathrm{x} /$ vocal tone show global positive spatial correlation, while spatial clustering is insignificant for /ä/ vocal tones. This situation may be due to the small number of emigrant villages and their dispersed settlement within the boundaries of the province. In this study, whether a relation exists between Turkish groups speaking Oghuz dialect who settled in Eskişehir in different time periods was investigated based on the use of $/ \mathrm{y} /, \mathrm{x} /$ and /ä/ vocal tones.

- $\quad / \mathrm{y} /$ vocal tone is used by Manavs, Yörüks and Turkmens. It is understood that these groups also use $/ \mathrm{y} /$ vocal tone with different frequencies. This vocal tone is mostly used by Manavs, followed by Yörüks and Turkmens.

- $\quad$ The use /x/ vocal tone is significant for Yörüks and Turkmens. It was found that Turkmens use / $\mathrm{x}$ / vocal tone quite often when compared to Yörüks.

- $\quad / a ̈ /$ vocal tone is used by Balkan immigrants.

The results obtained from numerous studies that have been conducted by using qualitative research methods were achieved by using quantitative research methods. Therefore, this is a pioneering study in terms of the use of spatial statistical methods in relation with language and dialect characteristics. The correlations determined by spatial statistics will be guiding to obtain objective and reproducible results in geolinguistic studies. The method applied has an innovative perspective on language researches. The use of spatial statistical methods in dialect researches will contribute to the literature and application studies. This method which is used with the vocal tones for Turkish, a head-final language, can also be used for head-initial, radical, or inflected languages. 
